\title{
ENERGY AND SUSTAINABILITY ASSESSMENT OF MUNICIPAL WASTEWATER TREATMENT UNDER CIRCULAR ECONOMY PARADIGM
}

\author{
ANDREY V. KISELEV ${ }^{1,2}$, ELENA R. MAGARIL ${ }^{2}$ \& ELENA CRISTINA RADA ${ }^{3}$ \\ ${ }^{1}$ Department of Investment Program, Municipal Unitary Enterprise for Water Supply and Sewerage, Russia \\ ${ }^{2}$ Department of Environmental Economics, Ural Federal University, Russia \\ ${ }^{3}$ Department of Theoretical and Applied Science, Insubria University, Italy
}

\begin{abstract}
Climate change and anthropogenic pollution have put limited water resources under pressure. Lack of basic sanitation services as well as the discharge of improperly treated effluent from wastewater treatment plants (WWTP) result in the deposition of large amounts of organic matter and nutrients, which have major detrimental effects on health. Wastewater treatment (WWT) can reduce water pollution but at the cost of increasing energy consumption and the corresponding atmosphere and climate problems. Sustainable WWT management is a global challenge to preserve fresh water and decrease energy consumption. Nowadays it becomes obvious that existing WWTP operation model, based on the linear "take-make-dispose" pattern, is no longer sustainable. Furthermore, disposal of a product in landfill means that all residual energy is lost. The adoption of circular economy (CE) practices with its $3 \mathrm{R}$ principles of reducing, reusing and recycling material appears as a timely, relevant and practical option to meet the goals of sustainable development. WWTP is a critical element in CE implementation policy and to measure the degree of "circularity" there is a need for indicators. This study considers the holistic overview of measuring the progress of CE implementation at WWTP under $3 \mathrm{R}$ principles using life cycle analysis (LCA) and material flow analysis (MFA) frameworks. The paper presents the principles of $\mathrm{CE}$ indicators set construction using managerial approach. The proposed set of indicators and integral circularity index are studied under three scenarios, based on real performance of northern and southern WWTP in Ekaterinburg, Russia. This study provides an efficient assessment tool of CE progress, which is rather simple for calculation and interpretation and suitable for the use of wide range of stakeholders.
\end{abstract}

Keywords: circular economy, wastewater treatment, sustainable management, energy flow, material flow, assessment, circularity index.

\section{INTRODUCTION}

Water scarcity is one of the main problems faced by many societies in the 21 st century and will become one of the most sensitive environmental issues in the coming decades [1]. At the current time, more than 2 billion people are living with the risk of reduced access to freshwater resources and by 2050 , at least one in four people is likely to live in a country affected by chronic or recurring shortages of fresh water [2].

Climate change and anthropogenic pollution have put limited water resources under pressure. Lack of basic sanitation services as well as the discharge of improperly treated effluent from wastewater treatment plants (WWTP) result in the deposition of large amounts of organic matter and nutrients, which have major detrimental effects on health [3]. As the result, eutrophication of surface water and coastal zones is expected to increase almost everywhere until 2030 [4]. Wastewater treatment (WWT) can reduce water pollution but at the cost of increasing energy consumption and the corresponding atmosphere and climate problems [5], [6]. Different solution for wastewater management are present in over the word demonstrating the necessity to find a sustainable and friendly solution from environmental, economic and energy point of view [7]-[9]. 
Sustainable WWT management is a global challenge to preserve fresh water and decrease energy consumption. According to UNESCO [10], at present only $20 \%$ of globally produced wastewater receives proper treatment with generation about 140 million tons of dry matter sewage sludge. The last figure was counted, using EurObserv'ER Report [11] with approximation on world's population. WWT process requires significant amounts of energy ranging from 250 to $500 \mathrm{kWh} /$ million $\mathrm{L}$ of treated wastewater with the growth perspective by $44 \%$ up to 2030 , especially for non-OECD countries, where wastewater currently receives little or no treatment [10].

Nowadays it becomes obvious that existing WWTP operation model, based on the linear "take-make-dispose" pattern, in no longer sustainable. Furthermore, disposal of a product in landfill means that all residual energy is lost [12], [13]. Now, the adoption of circular economy (CE) practices appears as a timely, relevant and practical option to meet the goals of sustainable development [14].

$\mathrm{CE}$ is a sustainable development strategy that is being proposed to tackle urgent problems of environmental degradation and resource scarcity. CE with its $3 \mathrm{R}$ principles of reducing, reusing and recycling material clearly illustrates the strong linkages between the environment and economics [15]. A sustainable system is characterized, among others, by a much reduced use of renewable and non-renewable inputs and closed loop reuse and recycling of material outputs, thus drastically reducing or eliminating waste and dissipative loss [16].

WWTPs possess a large potential to improve WWT in order to reduce insufficiently treated effluent and recover wastewater resources such as nutrients, energy, and the water itself [17].

One of the critical questions in the CE policy implementation is how we should measure its performance, since its objectives are substantially different from those in the traditional linear economy [18]. The core idea of measuring "circularity" is to see how materials are enter, flow within and (eventually) leave the economy [19]. The monitoring framework aimed at assessment the progress of $\mathrm{CE}$ implementation throughout different dimensions at all stages of lifecycle resources, products and services. To assess progress towards a more $\mathrm{CE}$ and the effectiveness of action, it is important to have a set of reliable indicators [20]. WWTP is a critical element in CE implementation policy and to measure the degree of "circularity" there is a need for a set of indicators.

The analysis of literature shows that most of existing studies are devoted to CE monitoring framework based on reuse and recycle applications. CE is not only reuse or recycle applications, but also reduce practices implementation, especially relevant for developing countries. That is why $3 \mathrm{R}$ principles should be taken into account within CE monitoring framework of WWTP. Moreover, proposed indicators are complex for calculations and require access to large amount of input data.

The more complex and intensive WWT process, the greater energy consumption, thus the aim of current research is to create the monitoring framework of WWTP efficiency under CE principles in order to ensure the proper quality of discharged wastewater with moderate energy consumption. This study considers the holistic overview of measuring the progress of CE implementation at WWTP under 3R principles using life cycle analysis (LCA) and material flow analysis (MFA) frameworks. Flows of material and energy are the core of circular economy and hence circular economy indicators should be able to capture these dimensions [12], [13], [16].

\section{MATERIALS AND METHODS}

The developed by authors method includes the following steps: (i) study area description; (ii) monitoring framework design using LCA and MFA under 3R principle; (iii) CE indicators 
set for WWTP definition; and (iv) integral circularity index development. A managerial approach is used for results interpretation, ranging output values for all $\mathrm{CE}$ indicators from 0 (which mean perfect linearity) to 1 (which mean perfect circularity).

\subsection{Investigated scenarios definition}

Three scenarios for WWTP operation systems are considered within this paper (Fig. 1) based mainly on the centralized sewerage system of Ekaterinburg, Russia. Ekaterinburg is the fourth largest city in the Russian Federation with the population of 1,468,833 inhabitants [21]. It is the administrative centre of the Sverdlovsk region, located on the border of Europe and Asia, the largest industrial, educational, scientific, touristic, commercial and financial center, as well as a transport and logistics hub.

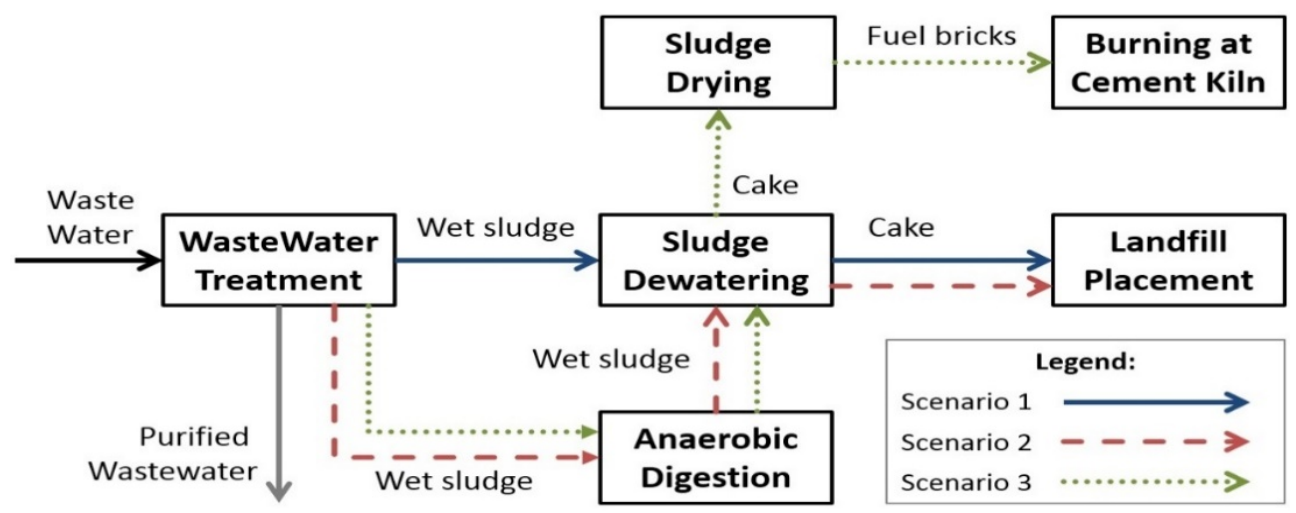

Figure 1: Investigated scenarios definition. (a) Scenario 1, based on southern WWTP in Ekaterinburg, Russia; (b) Scenario 2, based on northern WWTP in Ekaterinburg, Russia; (c) Scenario 3, based on best available techniques.

The Ekaterinburg sewerage system has been built on the basin principle: two main sewerage zones can be identified within the city - northern and southern ones. WWT from these zones is carried out at the northern and southern WWTP, respectively. The southern WWTP was designed in 1970 with maximum wastewater inflow up to 550,000 $\mathrm{m}^{3}$ per day, while the northern one has maximum performance up to $100,000 \mathrm{~m}^{3}$ per day.

The first scenario shown at Fig. 1 is based on the WWT process actually performed at southern WWTP. WWT includes primary (mechanical) and secondary (biological) treatment with chlorine disinfection before discharge. Sewage sludge treatment include mechanical dewatering with cake placement at landfills. This WWTP operates without significant modernization since its foundation and has obsolete technologies.

The second scenario shown at Fig. 1 is based on the WWT process actually performed at northern WWTP. The basic WWT operations are similar to southern WWTP, however in 2018 total modernization of the process line was finished, introducing best available techniques (BAT) including rotary drum fine screens, sand traps with aeration, aeration tanks with nitrification and denitrification, UV-disinfection before discharge and others. Sewage sludge treatment include anaerobic digestion with biogas generation and mechanical dewatering. Biogas CHP-unit installation is planned in nearest future. 
The third scenario shown in Fig. 1 is based on the second scenario supplemented with company's future modernization plans, including sewage sludge drying with incineration at cement kiln.

\subsection{Methodology framework for construction of CE indicators}

This study was performed using LCA and MFA framework as a basic model for CE indicators construction under $3 \mathrm{R}$ principles of $\mathrm{CE}$.

LCA is related to the ISO 14000 environmental management standard. LCA is the assessment of the environmental impact of a given product throughout its lifespan. The goal of LCA is to compare the environmental performance of products in order to be able to choose the least burdensome [22]. All activities and processes result in environmental impacts due to consumption of resources, emissions of substances into the natural environment, and other environmental exchanges [23]. LCA technique has a step-by-step practice according to ISO 14040:2006, including four stages: (i) goal and scope definition; (ii) inventory analysis; (iii) impact analysis; and (iv) interpretation of results.

The approach with most direct relevance for CE indicators is MFA, based on the principles and methods of mass balancing and input-output analysis [16]. MFA is an accounting system that captures the mass balances in an economy, where inputs are equal to outputs, and based on fundamental principles, specifically the laws of thermodynamics [24]. The core idea of MFA is to specify and quantify the pathways of materials/energy into, through and out of specified system boundaries [25]. It is expressed in material flows monitoring using physical units (weight) and its qualitative rating.

The purpose of this study is not the use of the LCA and MFA techniques in step-by-step actions within selected scenarios, but the use of these tools as a framework in construction of the CE indicators. In this way, WWTP LCA framework, developed by Buonocore et al. [23], was taken as a basic model for further work. This framework has undergone some improvements with MFA elements and matches all scenario under consideration (Fig. 2).

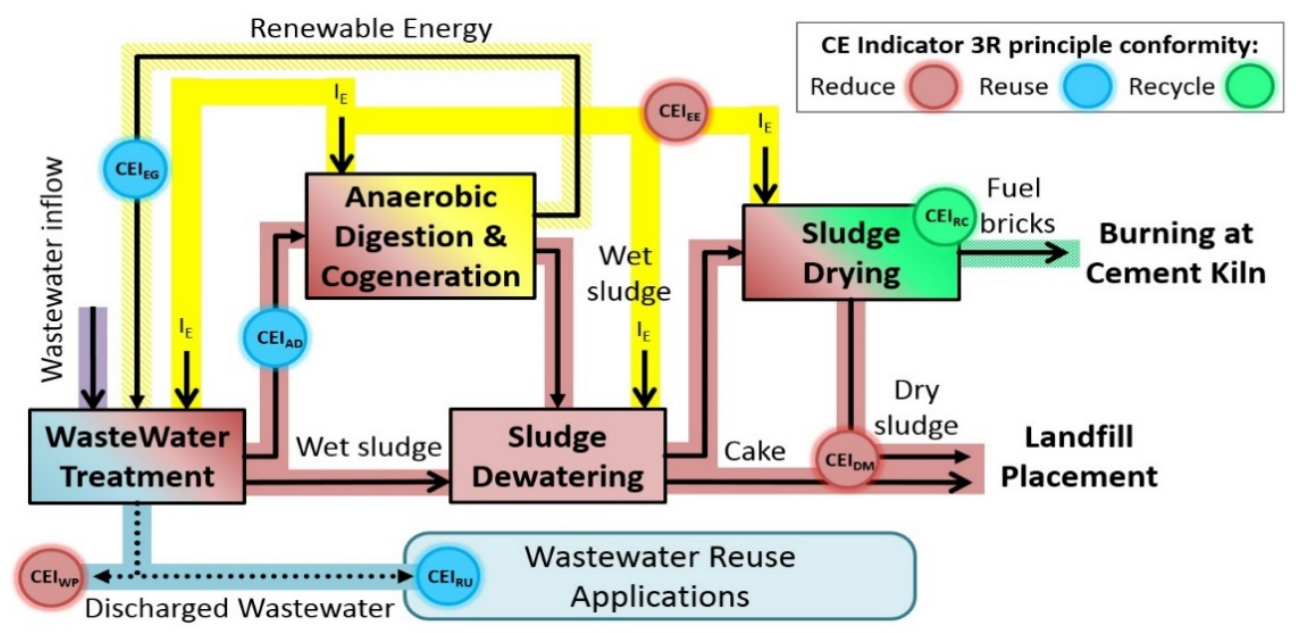

Figure 2: $\mathrm{CE}$ indicators set under $3 \mathrm{R}$ principle. Blue line $=$ wastewater flow; red line $=$ sewage sludge flow; yellow line = energy flow; green line = recycled sewage sludge flow. 
Main streams of materials were determined including wastewater as an inflow, purified wastewater and sludge as outflow. It is worth noting the separate flow of recycled sludge as the possible option for WWTP. Energy flow is also considered within selected framework, including energy input from grid and renewable energy from anaerobic digestion. CE indicators are derived from considered framework (Fig. 2) as outflow checkpoints, which corresponds to the transition towards $\mathrm{CE}$ within 3R categories.

Analysis of review papers allowed to construct $\mathrm{CE}$ indicator set, which implies single $\mathrm{CE}$ indicator for each 3R category within any flow, except recycle - in this category only sewage sludge is possible to recycle. As the result, seven CE indicators make up a set for energy and sustainability assessment of municipal WWT under CE paradigm. This set include:

1. Reduce $\mathrm{CE}$ indicator for wastewater flow $\left(C E I_{W P}\right)$.

2. Reduce $\mathrm{CE}$ indicator for sewage sludge flow $\left(C E I_{D M}\right)$.

3. Reduce $\mathrm{CE}$ indicator for energy flow $\left(C E I_{E E}\right)$.

4. Reuse $\mathrm{CE}$ indicator for wastewater flow $\left(C E I_{R U}\right)$.

5. Reuse $C E$ indicator for sewage sludge flow $\left(C E I_{A D}\right)$.

6. Reuse CE indicator for energy flow $\left(C E I_{E G}\right)$.

7. Recycle CE indicator for sewage sludge flow $\left(C E I_{R C}\right)$.

\subsubsection{Reduce CE indicator for wastewater flow}

$C E I_{W P}$ measures the efficiency of WWT. The basic principle was mentioned by Rukavishnikova et al. [26] within the WWT quality assessment approach using multiplicity of wastewater samples with some improvements by the authors. Multiplicity $(M)$ is the intensity of negative exposure of harmful substances (pollutants) on the water body [22]. Multiplicity of pollutant $\mathrm{i}$ is calculated as follows:

$$
M_{i}=\frac{C_{i}^{P}}{M P C_{i}^{P}}
$$

where $C_{i}^{P}=$ annual average concentration of i substance and $M P C_{i}^{P}=$ maximum permissible concentration of i substance. The most critical pollutants for WWTP BAT technology conformity were identified by the authors, including: (i) suspended solids; (ii) biochemical oxygen demand in 20 days $\left(\mathrm{BOD}_{20}\right)$; (iii) phosphorus phosphate; (iv) nitrate-ion; (v) nitriteion; and (vi) nitrogen ammonia. $C E I_{W P}$ is calculated as follows:

$$
C E I_{W P}=\frac{\sum_{i=1}^{6} M W_{i}}{6}
$$

where $M W_{i}=$ multiplicity weight of each substance.

Multiplicity weight is an expert evaluation of multiplicity in relation to the CE. It means that the more pollutants above the allowed MPC enters the water bodies, the lower the CE indicator value. Multiplicity weight values are presented in Table 1.

Table 1: Multiplicity weight values.

\begin{tabular}{|l|c|c|c|c|}
\hline \multirow{2}{*}{} & \multicolumn{4}{|c|}{ Multiplicity value $(M)$} \\
\cline { 2 - 5 } & $0 \leq \mathrm{M} \leq 1$ & $1<\mathrm{M} \leq 5$ & $5<\mathrm{M} \leq 15$ & $\mathrm{M}>15.01$ \\
\hline Multiplicity weight $\left(M W_{i}\right)$ & 1.00 & 0.50 & 0.25 & 0.00 \\
\hline
\end{tabular}

Further investigations can set additional rates for multiplicity weight values considering the difference in hazard degree of substances. 
2.2.2 Reduce CE indicator for sewage sludge flow

The volume of output sewage sludge depends on the dry matter (DM) content and applied dewatering techniques. Water removal is the primary solution of volume reduction [27]: the more DM content in sewage sludge - the less WWTP personnel is required to export it the landfills. Thus, the progress of CE is directly proportional to DM content of sewage sludge ready for export to landfills. $C E I_{D M}$ is calculated as follows:

$$
C E I_{D M}=\mathrm{DM}=\frac{M_{S S}^{D M}}{M_{S S}},
$$

where, $M_{S S}^{D M}=$ total mass of dry mater in sewage sludge, and $M_{S S}=$ total mass of sewage sludge. In some cases, e.g. when the sewage sludge is subjected to drying and subsequent use as a biofuel for incineration at cement kilns (in other words, it is recycled), placement on landfills is not performed, thus $C E I_{D M}=1$ (waste is completely transformed into resource).

\subsubsection{Reduce CE indicator for energy flow}

$C E I_{E E}$ measures the efficiency of WWTP's energy consumption. $C E I_{E E}$ is selected according to net energy efficiency weight values (Table 2), designed by authors, using specific net energy efficiency indicator $\left(E E_{N E T}\right)$, which is calculated as follows:

$$
E E_{N E T}=\frac{E C_{T}-E G_{R}}{Q_{T W W}},
$$

where, $E C_{T}=$ total WWTP energy consumption, related to the full WWT cycle, including sludge treatment, $E G_{R}=$ total WWTP self-generated energy from renewable sources (e.g. biogas), $Q_{T W W}=$ total volumetric flow of treated wastewater. Net energy efficiency weight is an expert evaluation of net energy efficiency in relation to the CE (see Table 2). This interpretation was set up according to the typical WWTP energy consumption, mentioned by Electric Power Research Institute and Water Research Foundation [28] and Gandiglio et al. [29] and is given for two different WWTP scales.

Table 2: Net energy efficiency weight values.

\begin{tabular}{|c|c|c|c|}
\hline \multirow{2}{*}{$\#$} & \multirow{2}{*}{$E E_{N E T}$ Value $\left(\mathrm{kWh} / \mathrm{m}^{3}\right)$} & $C E I_{E E}$ & $C E I_{E E}$ \\
\cline { 3 - 4 } & $E E_{N E T} \leq 0.300$ & $\mathrm{~V} \geq 30,000 \mathrm{~m}^{3} /$ day & $\mathrm{V} \leq 30,000 \mathrm{~m}^{3} /$ day \\
\hline 1 & $0.300<E E_{N E T} \leq 0.440$ & 0.80 & 1.00 \\
\hline 2 & $0.440<E E_{N E T} \leq 0.700$ & 0.60 & 1.00 \\
\hline 3 & $0.700<E E_{N E T} \leq 1.000$ & 0.40 & 0.80 \\
\hline 4 & 0.00 & 0.60 \\
\hline 5 & $1.000<E E_{N E T} \leq 1.500$ & 0.20 & 0.40 \\
\hline 6 & $1.500<E E_{N E T} \leq 1.800$ & 0.00 & 0.20 \\
\hline 7 & $E E_{N E T}>1.800$ & 0.00 & 0.00 \\
\hline
\end{tabular}

2.2.4 Reuse CE indicator for wastewater flow

$C E I_{R U}$ measures the reuse of already treated wastewater. Similar indicator was mentioned by Molina-Sánchez et al. [30], Geng et al. [24] and is defined as the treated wastewater flow that can be obtained and reused by alternative users, for example for irrigation or communal (e.g. streets washing) purposes. $C E I_{R U}$ is calculated as follows: 


$$
C E I_{R U}=\frac{Q_{R U}}{Q_{T W W}}
$$

where $Q_{R U}=$ volumetric flow of reused wastewater, $Q_{T W W}=$ total volumetric flow of treated wastewater.

\subsubsection{Reuse CE indicator for sewage sludge flow}

Nowadays sewage sludge anaerobic digestion is considered to be state-of-the-art technique for the efficient sewage sludge management. $C E I_{A D}$ is calculated as follows:

$$
C E I_{A D}=\frac{Q_{A D}}{Q_{T S S}}
$$

where $Q_{A D}=$ volumetric flow of sewage sludge that has been processed stabilization through anaerobic digestion, $Q_{T S S}=$ total volumetric flow of generated sewage sludge.

2.2.6 Reuse CE indicator for energy flow

$C E I_{E G}$ is closely related to $C E I_{A D}$ and has directly proportional relationship. Pinter [16] mentioned similar indicators in measuring the progress towards "sound material cycle" and included it in his indicator set for material and energy flows. $C E I_{E G}$ measures the share of generated renewable energy in total WWTP energy consumption and is calculated as follows:

$$
C E I_{E G}=\frac{E G_{R}}{E C_{T}}
$$

where, $E G_{R}=$ total WWTP self-generated energy from renewable sources (e.g. biogas), $E C_{T}$ $=$ total WWTP energy consumption. There is a possibility that the rate of energy generation exceeds the rate of energy consumption, however we are considering indicators at micro (company's) level and the main "circularity" issue is to cover own energy consumption.

\subsubsection{Recycle CE indicator for sewage sludge flow}

$C E I_{R C}$ is the only one indicator in the recycle category. $C E I_{R C}$ measures the recycle rate of dewatered sewage sludge (or cake). For instance, recycling can be fulfilled through sludge drying and producing organic fuel bricks for further use in cement kiln for the manufacturing of Portland cement. $C E I_{R C}$ is calculated as follows:

$$
C E I_{R C}=\frac{M_{T D S S}^{R c l}}{M_{T D S S}},
$$

where, $M_{T D S S}^{R c l}=$ total mass of recycled dewatered sewage sludge, $M_{T D S S}=$ total mass of dewatered sewage sludge.

\subsection{Integral circularity index}

Integral circularity index $(I C I n)$ is intended to integrate the results of $\mathrm{CE}$ indicators set (mentioned in Sections 2.2.1-2.2.7). This indicator should reflect the progress towards CE without distortion at the similar output values range. Each of three $3 \mathrm{R}$ categories has the same importance for CE progress as well as three types of flow. Thus, ICIn is calculated as follows:

$$
\operatorname{ICIn}=\frac{\sum_{i=1}^{7} C E I_{i}}{7}
$$




\section{RESULTS AND DISCUSSIONS}

The period from 2014 to 2018 was chosen to perform the proposed method for WWTP CE implementation progress assessment. Scenarios 1 and 2 have calculated values throughout the period mentioned above, while Scenario 3 is based on Scenario 2 with some adjustments (under modernization plans) and focused on the future perspective, starting from 2018. In other words, Scenario 3 has two time points: "2018" (which is equal to Scenario 2 CE Indicator values) and "future perspective".

Table 3 shows the result of an experiment conducted under considered scenarios using data from southern and northern WWTPs, situated in Ekaterinburg (Russia).

Table 3: CE indicators set and integral circularity index for Ekaterinburg WWTP.

\begin{tabular}{|c|c|c|c|c|c|c|c|c|c|c|}
\hline \multirow{2}{*}{ \# } & \multirow{2}{*}{ Scenario } & \multirow{2}{*}{ Year } & \multicolumn{8}{|c|}{ CE Indicators } \\
\hline & & & $C E I_{W P}$ & $C E I_{D M}$ & $C E I_{E E}$ & $C E I_{R U}$ & $C E I_{A D}$ & $C E I_{E G}$ & $C E I_{R C}$ & ICIn \\
\hline 1 & \multirow{5}{*}{1} & 2014 & 0.50 & 0.25 & 0.80 & 0.00 & 0.00 & 0.00 & 0.00 & 0.22 \\
\hline 2 & & 2015 & 0.50 & 0.25 & 0.80 & 0.00 & 0.00 & 0.00 & 0.00 & 0.22 \\
\hline 3 & & 2016 & 0.50 & 0.25 & 0.80 & 0.00 & 0.00 & 0.00 & 0.00 & 0.22 \\
\hline 4 & & 2017 & 0.42 & 0.25 & 0.60 & 0.00 & 0.00 & 0.00 & 0.00 & 0.18 \\
\hline 5 & & 2018 & 0.46 & 0.25 & 0.60 & 0.00 & 0.00 & 0.00 & 0.00 & 0.19 \\
\hline 6 & & 2014 & 0.75 & 0.17 & 0.80 & 0.00 & 0.00 & 0.00 & 0.00 & 0.25 \\
\hline 7 & & 2015 & 0.71 & 0.17 & 1.00 & 0.00 & 0.00 & 0.00 & 0.00 & 0.27 \\
\hline 8 & & 2016 & 0.75 & 0.17 & 0.80 & 0.00 & 0.00 & 0.00 & 0.00 & 0.25 \\
\hline 9 & & 2017 & 0.58 & 0.25 & 0.80 & 0.00 & 0.00 & 0.00 & 0.00 & 0.23 \\
\hline 10 & & 2018 & 0.67 & 0.25 & 0.80 & 0.00 & 1.00 & 0.00 & 0.00 & 0.39 \\
\hline 11 & \multirow{2}{*}{3} & 2018 & 0.67 & 0.25 & 0.80 & 0.00 & 1.00 & 0.00 & 0.00 & 0.39 \\
\hline 12 & & F.p.* & 0.67 & 1.00 & 1.00 & 0.00 & 1.00 & 0.67 & 1.00 & 0.76 \\
\hline
\end{tabular}

*Future perspective.

$\mathrm{CE}$ is not only reuse and recycle applications, but also reduce ones, especially popular in developing countries. Thus, the use of $3 \mathrm{R}$ principle within the set of indicators is of a great importance. According to survey results, the first three $\mathrm{CE}$ indicators from reduce category have more sound values in comparison with reuse and reduce categories. These values make up the main part of integral circularity index. To some extent, reduce applications can be considered the first step towards CE. Reduction refers to minimize the input of primary energy and raw materials through the improvement of production efficiency [31].

Reuse of goods or resources suggests the use of a product again for the same purpose in its original form or with little enhancement or change [12]. Wastewater reclamation is considered one of the recommended solutions for the problem of water scarcity. Some countries, including Cyprus, France, Greece, Spain, Italy and Portugal, have standards developed specially for the reuse of treated wastewater [1]. Recycle encourages processing the recyclable materials into new products so that the consumption of virgin materials can be reduced. These principles, as parts of the whole process, have different hierarchical importance, with the reduction of resources used as the leading principle within a circular economy system [31]. 
The progress towards CE for scenarios under consideration starting from 2014 in terms of integral circularity index is presented in Fig. 3.

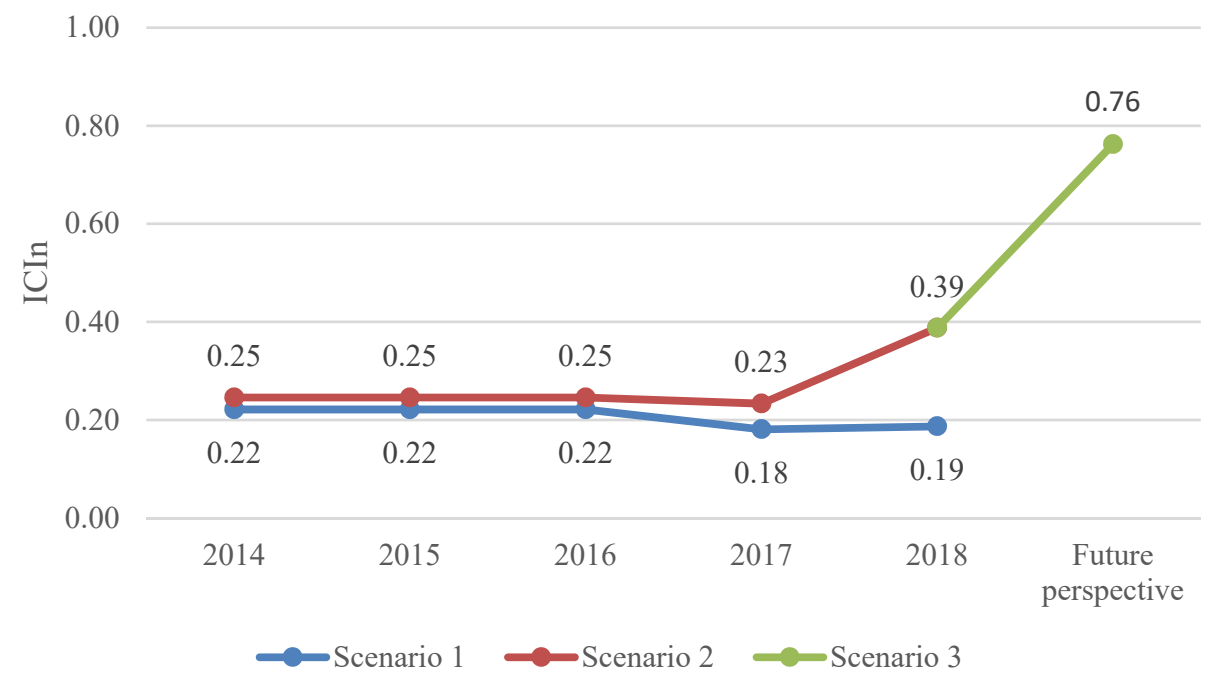

Figure 3: The progress towards CE for Ekaterinburg WWTPs.

The results show that current investment strategy for Ekaterinburg WWTP inevitably leads towards CE. The uprising trend of ICIn for scenario 2 refers to successful implementation of modernization project for northern WWTP in 2018 with full WWT technology upgrade. Next step towards CE for northern WWTP includes CHP-unit installation and the construction of sewage sludge drying plant, which is referred to scenario 3 . In this way, northern WWTP can achieve $76 \%$ of circularity. On the other hand, southern WWTP is going towards linearity and there is a strong need for deep modernization using proven solutions that are already applied at northern WWTP.

The reuse of effluent (e.g. for irrigation) in Russian Federation and some other countries is limited by legal or sanitary restrictions or stumble over cultural issues (some people are disgusted if they find out that crops are produced with treated domestic wastewater) thus the achievement of high circularity rates is difficult. However, there is an alternative to use effluent for industrial and communal purposes, e.g. streets cleaning, cooling for machines and mechanisms, centralized heating, construction of objects etc.

\section{CONCLUSION}

The proposed set of indicators and integral circularity index create an efficient assessment tool, which is rather simple for calculation and interpretation and suitable for the use of wide range of stakeholders. In comparison with reviewed papers this tool does not require significant input data and is easy to understand to what extent the WWTP is circular or linear.

It is important tool for governments and business to measure the progress towards CE. Moreover, integral circularity index can be used as a benchmark for WWTP sector within region, country or worldwide to promote continuous improvement and best practice exchange. 
However, there are some limitations for applying this approach. CE indicators set is based on the principle of measuring the average values of each flow (e.g. volumetric units) and doesn't take into account the scale of WWTP. There are possible options when integrated circularity index is close to maximum values, but the component of WWT quality is moderate and within a large scale WWTP a huge amount of waste load enters the water bodies. Further researches with different $\mathrm{CE}$ indicator weights under multiscale framework for Integral circularity index construction are expected.

\section{ACKNOWLEDGEMENT}

This research was supported by Act 211 Government of the Russian Federation, contract № 02.A03.21.0006.

\section{REFERENCES}

[1] Pintilie, L., Torres, C.M., Teodosiu, C. \& Castells, F., Urban wastewater reclamation for industrial reuse: An LCA case study. Journal of Cleaner Production, 139, pp. 114, 2016. DOI: 10.1016/j.jclepro.2016.07.209.

[2] United Nations Sustainable Development, www.un.org/sustainabledevelopment. Accessed on: 29 Apr. 2019.

[3] Naidoo, S. \& Olaniran, A.O., Treated wastewater effluent as a source of microbial pollution of surface water resources. Int. J. Environ. Res. Public Health, 11, pp. 249270, 2014. DOI:10.3390/ijerph110100249.

[4] United Nations Department of Economic and Social Affairs, Back to our common future: Sustainable development in the 21st century (SD21) project, 2012. https://sustainabledevelopment.un.org/content/documents/UN-DESA_Back_ Common_Future_En.pdf. Accessed on: 29 Apr. 2019.

[5] Niu, K., Wu, J., Qi, L. \& Niu, Q., Energy intensity of wastewater treatment plants and influencing factors in China. Science of the Total Environment, 670, pp. 961-970, 2019. DOI: 10.1016/j.scitotenv.2019.03.159.

[6] Pajares, E.M., Valero, L.G. \& Sánchez, I.M.R., Cost of urban wastewater treatment and ecotaxes: Evidence from municipalities in southern Europe. Water, 11(3), p. 423, 2019.

[7] Langone, M. et al., Application of a novel hydrodynamic cavitation system in wastewater treatment plants. UPB Scientific Bulletin, Series D, 77(1), pp. 225-234, 2015.

[8] Ragazzi, M., Catellani, R., Rada, E.C., Torretta, V. \& Salazar-Valenzuela, X., Management of urban wastewater on one of the Galapagos Islands. Sustainability, 8(3), p. 208, 2016.

[9] Eggimann, S., Truffer, B., Feldmann, U. \& Maurer, M., Screening European market potentials for small modular wastewater treatment systems: An inroad to sustainability transitions in urban water management? Land Use Policy, 78, pp. 711-725, 2018.

[10] UNESCO, Managing water under uncertainty and risk, the UN world water development report 4, vol. 1, 2012. http://unesdoc.unesco.org/images/0021/002156/ 215644e.pdf. Accessed on: 29 Apr. 2019.

[11] EurObserv'ER, The state of renewable energies in Europe. Edition 2016. www.eurobserv-er.org/pdf/2016/EurObservER-Annual-Overview-2016-EN.pdf. Accessed on: 12 Mar. 2019.

[12] Ellen MacArthur Foundation, Towards the circular economy: economic and business rationale for an accelerated transition, 2013. 
[13] Ellen MacArthur Foundation, Circularity indicators: An approach to measuring circularity. Methodology, 2015. www.ellenmacarthurfoundation.org/assets/ downloads/insight/Circularity-Indicators_Methodology_May2015.pdf. Accessed on: 29 Apr. 2019.

[14] Saidani, M., Yannou, B., Leroy, Y., Cluzel, F. \& Kendall, A., A taxonomy of circular economy indicators. Journal of Cleaner Production, 207, pp. 542-559, 2019.

[15] Heshmati, A., A review of the circular economy and its implementation. IZA Discussion Paper, No. 9611, 2015.

[16] Pinter, L., International experience in establishing indicators for the circular economy and considerations for China. Report for the Environment and Social Development Sector Unit, East Asia and Pacific Region, The World Bank, 2006.

[17] van Leeuwen, K., de Vries, E., Koop, S. \& Roest, K., The energy and raw materials factory: role and potential contribution to the circular economy of the Netherlands. Environmental Management, 61, pp. 786-795, 2018.

DOI: $10.1007 / \mathrm{s} 00267-018-0995-8$.

[18] EASAC, Policy Report 2016, Indicators for circular economy. www.easac.eu/fileadmin/PDF_s/reports_statements/Circular_Economy/EASAC_ Indicators_web_complete.pdf. Accessed on: 29 Apr. 2019.

[19] Communication from the commission to the European Parliament, the Council, the European economic and social committee and the committee of the regions on a monitoring framework for the circular economy, Strasbourg, 2018.

[20] EC-European Commission Closing the Loop - an EU Action Plan for the Circular Economy, The Circular Economy Package Proposal, Brussels, Belgium, 2015.

[21] Wikipedia, Population of Ekaterinburg. (In Russian.) https://ru.wikipedia.org/wiki/Население_Екатеринбурга. Accessed on: 29 Apr. 2019.

[22] ISO 14040:2006, Environmental management: Life cycle assessment. www.iso.org/standard/37456.html. Accessed on: 29 Apr. 2019.

[23] Buonocore, E., Mellino, S., De Angelis, G., Liu, G. \& Ulgiati, S., Life cycle assessment indicators of urban wastewater and sewage sludge treatment. Ecological Indicators, 94, pp. 13-23, 2018. DOI: 10.1016/j.ecolind.2016.04.047.

[24] Geng, Y., Fu, J., Sarkis, J. \& Xue, B., Towards a national circular economy indicator system in China: An evaluation and critical analysis. Journal of Cleaner Production, 23, pp. 216-224, 2012.

[25] Cai, Z.C. \& Wennerstern, R., Ecological urban design through material and energy flow analysis and life cycle assessment: From an architect's perspective. WIT Transactions on Ecology and the Environment, vol. 142, pp. 3-13, 2010.

[26] Rukavishnikova, I., Kiselev, A., Berezyuk, M. \& Ashirova, I., Improvement of the methodology for assessing domestic wastewater treatment quality using benchmarking tools. WIT Transactions on Ecology and the Environment, vol. 228, pp. 209-219, 2018.

[27] Kiselev, A., Magaril, E., Magaril, R., Panepinto, D., Ravina, M. \& Zanetti, M.C., Towards circular economy: Evaluation of sewage sludge biogas solutions. Resources, 8(2), p. 91, 2019. DOI: 10.3390/resources8020091.

[28] Electric Power Research Institute and Water Research Foundation, Electricity use and management in the municipal water supply and wastewater industries, 2013.

[29] Gandiglio, M., Lanzini, A., Soto, A., Leone P. \& Santarelli M., Enhancing the energy efficiency of wastewater treatment plants through co-digestion and fuel cell systems. Frontiers in Environmental Science, 5(70), 2017. 
120 Energy and Sustainability VIII

[30] Molina-Sánchez, E., Leyva-Díaz, J.C., Cortés-García, F.J. \& Molina-Moreno, V., Proposal of sustainability indicators for the waste management from the paper industry within the circular economy model. Water, 10(1014), 2018. DOI: $10.3390 / \mathrm{w} 10081014$.

[31] Su, B., Heshmati, A., Geng, Y. \& Yu, X., A review of the circular economy in China: Moving from rhetoric to implementation. Journal of Cleaner Production, 42, pp. 215227, 2013. DOI: 10.1016/j.jclepro.2012.11.020. 